Article

\title{
Fungicide Tebuconazole Influences the Structure of Human Serum Albumin Molecule
}

\author{
Katarína Želonková ${ }^{1}$, Samuel Havadej ${ }^{1}$, Valéria Verebová ${ }^{2}$, Beáta Holečková ${ }^{3}$, Jozef Uličný ${ }^{1}$ (]) \\ and Jana Staničová $2,4, *$ \\ 1 Faculty of Science, Pavol Jozef Šafárik University, Jesenná 5, 04154 Košice, Slovakia \\ 2 Department of Chemistry, Biochemistry \& Biophysics, University of Veterinary Medicine \& Pharmacy, \\ Komenského 73, 04181 Košice, Slovakia \\ 3 Department of Biology \& Genetics, University of Veterinary Medicine \& Pharmacy, Komenského 73, \\ 04181 Košice, Slovakia \\ 4 First Faculty of Medicine, Charles University, Kateřinská 1, 12108 Prague, Czech Republic \\ * Correspondence: jana.stanicova@uvlf.sk; Tel.: +421-915-984-613
}

Received: 19 July 2019; Accepted: 1 September 2019; Published: 2 September 2019

\begin{abstract}
Studies of interactions between pesticides and target mammalian proteins are important steps toward understanding the pesticide's toxicity. Using calorimetric and spectroscopic methods, the interaction between triazole fungicide tebuconazole and human serum albumin has been investigated. The spectroscopic techniques showed that fluorescence quenching of human serum albumin by tebuconazole was the result of the formation of tebuconazole/human serum albumin complex with the static type as the dominant mechanism. The association constant was found to be $8.51 \times 10^{3} \mathrm{~L} / \mathrm{mol}$. The thermodynamic parameters were obtained as $\Delta \mathrm{H}=-56.964 \mathrm{~kJ} / \mathrm{mol}$, $\Delta S=-115.98 \mathrm{~J} / \mathrm{mol} \cdot \mathrm{K}$. The main active interactions forming the tebuconazole/human serum albumin complex were identified as the interplay between hydrogen bonds and/or van der Waals forces, based on thermodynamic experiments. These binding modes were corroborated well by the predictions of molecular modeling. Hydrogen bonding of tebuconazole with Arg222, Ala215 and Ala291 of human serum albumin played a relevant role in binding. The conformation changes in secondary structure were characterized by circular dichroism and 3D fluorescence spectra.
\end{abstract}

Keywords: tebuconazole; interaction; human serum albumin; spectroscopy; molecular modeling

\section{Introduction}

Pesticides are globally used for crop control. The industrial and agricultural means of food production are expected to increase, in particular, the quantity and quality of crops. On the other hand, the question arises whether using pesticides endangers the health of consumers. Knowledge about the effects and consequences of pesticide formulations' side-effects is necessary to prevent the use of inappropriate products or to limit the extent of their use. This knowledge also makes it possible to determine pesticide tolerances and their residual limits, especially in food and drink.

Tebuconazole [1-(4-chlorophenyl)-4,4-dimethyl-3-(1,2,4-triazol-1-ylmethyl)pentan-3-ol] (Figure 1) is a representative of the triazole class of fungicides, which are used in agriculture for disease control of cereal, vegetable, fruit and nut crops worldwide [1]. The antifungal activity of triazoles is due to their ability to inhibit the ergosterol biosynthesis pathway via inhibition of enzyme 14- $\alpha$-demethylase, which blocks the conversion of lanosterol to ergosterol and results in the arrest of fungal growth [2]. 


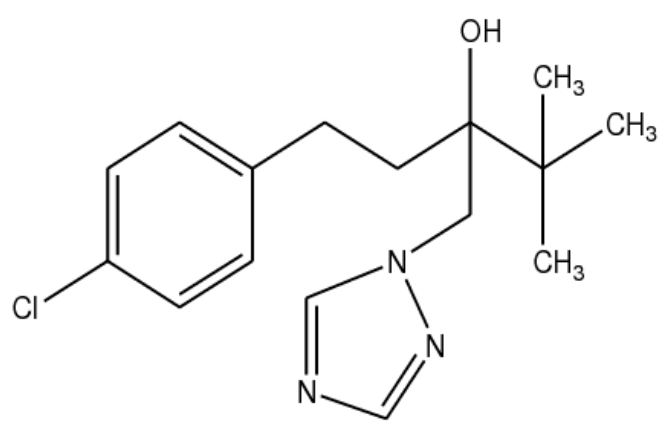

Figure 1. Structure of tebuconazole (TB).

Tebuconazole (TB) is the active ingredient used in Orius $25 \mathrm{EW}$, which is applied to a number of crops such as fruits, rice, vegetables and grapes, because of its broad-spectrum antifungal activity. The US EPA has classified TB as Group C-Possible Human Carcinogen [3]. TB has a half-life in soil of 49-610 days under aerobic conditions and exhibits moderate mobility [4,5]. It is classified as toxic to aquatic organisms [6] and its content in stream water has increased in recent years [7]. TB concentrations detected in surface waters were up to 175-200 $\mu \mathrm{g} / \mathrm{L}$ [8]. Yu and co-workers [9] have observed that exposure to TB can alter thyroid hormone levels as well as gene transcription in zebrafish larvae. The results obtained by Holečková et al. [10] indicated that TB can exert either cytotoxic and/or genotoxic effect on bovine peripheral lymphocytes. TB has been also found in farm workers with maximum concentrations of $19.2 \mu \mathrm{g} / \mathrm{L}$ and $2.22 \mathrm{ng} / \mathrm{kg}$ in urine and hair samples, respectively [11,12].

Mas et al. [13] synthesized $\mathrm{pH}$-sensitive gated mesoporous silica nanoparticles loaded with $\mathrm{TB}$. Interestingly, these nanodevices loaded with TB significantly enhanced TB cytotoxicity. The increase of TB action could potentially overcome the adverse side effects associated with topical therapies for vulvovaginal infection and significantly improve its cost-effectiveness.

Human serum albumin (HSA) is the most abundant protein in human plasma $(\sim 600 \mu \mathrm{M})$ with a typical concentration of $40 \mathrm{mg} / \mathrm{mL}$ in the bloodstream [14,15]. This protein contributes to a significant number of transport and regulatory processes and binds a wide variety of substrates such as amino acids, fatty acids, hormones, metals, and a broad spectrum of drugs [16-21]. HSA is a monomeric protein consisted of 585 amino acids with total molecular weight of $66,400 \mathrm{Da}$. HAS macromolecule is organized in three main domains (I, II, III), where each can be divided into two subdomains (A and B) containing 6 and 4 alpha-helixes, respectively.

Recently, several studies have been realized to examine the toxic effects of pesticides at the protein level [22-25], but information about the influence of triazoles on plasma proteins is still limited [26,27]. Binding of triazoles to plasma proteins has toxicological importance as it can significantly affect their distribution in and excretion from an organism [27]. Their penetration into the blood system can cause their binding to plasma proteins and afterwards induce some structure and function alteration in the protein.

The comprehensive study by Zhang et al. [26] explored the mechanism of interaction of the typical triazole fungicides with HSA using multispectroscopic techniques. They excluded determination of the binding properties of TB because of insufficient quenching of protein by TB. However, our preliminary calorimetric and spectroscopic studies [28] show significant effects of TB on HSA (fatty acid-free) thermal stability, absorption spectrum, and fluorescence quenching of protein by TB, suggesting that HSA is an important component of TB distribution. Thus, we repeated and extended our preliminary results including other spectroscopic techniques (far-UV circular dichroism spectroscopy, 3D fluorescence spectroscopy and site markers competitive experiments) to confirm and refine the TB influence on HSA structure. Molecular modeling was done with molecular docking to complement our experimental findings and to suggest their interpretation in molecular interaction terms.

In this study we complete the information about interactions of TB in relation to plasma protein (HSA) with regard to the above-mentioned preliminary results. This investigation might be beneficial 
in cases of frequent application of TB as pesticide. Moreover, our results may provide data required for clarifying the binding mechanisms of TB with HSA and might also be helpful for food safety and human health protection when TB is applied as an antifungal agent.

\section{Results and Discussion}

\subsection{Differential Scanning Calorimetry}

Thermal stability study of HSA, as well as investigation of the influence of ligand/HSA complex formation on this stability, can provide an initial view of the possible interaction between the protein and the fungicide. It is known, that ligand binding gives an increment in the thermal stability of protein due only to the coupling of binding with unfolding [29]. Faroongsarng [30] studied assessment of the dissociation energies of diazepam and ibuprofen bound on HSA by DSC method and found that the denaturation of HSA incubated with the drugs was done at higher temperatures than HSA itself depending on drugs' concentrations. Similar findings were demonstrated by other authors [31,32]. The thermograms of free HSA and HSA (fixed concentrations) in the presence of different TB concentrations are shown in Figure S1. The Table 1 summarizes thermodynamic parameters obtained from the thermograms in Figure S1.

Table 1. Thermodynamic parameters of denaturing complexes of human serum albumin (HSA) and TB/HSA.

\begin{tabular}{cccc}
\hline Ratio TB/HSA & $\mathbf{t}_{\mathbf{D} \mathbf{1}}\left({ }^{\circ} \mathbf{C}\right){ }^{*}$ & $\mathbf{t}_{\mathbf{D} 2}\left({ }^{\circ} \mathbf{C}\right)^{+}$ & $\Delta \boldsymbol{H}(\mathbf{k J} / \mathbf{m o l})$ \\
\hline 0 & 57.20 & 65.53 & 527.97 \\
$1 / 1$ & 57.86 & 67.08 & 604.75 \\
$5 / 1$ & 59.67 & 71.57 & 652.22 \\
$7 / 1$ & 60.46 & 72.93 & 710.02 \\
$10 / 1$ & 60.49 & 72.99 & 730.66 \\
\hline
\end{tabular}

* Denaturation temperature of the first transition. ${ }^{+}$Denaturation temperature of the second transition.

A slight shift in HSA denaturation temperature (more than $3{ }^{\circ} \mathrm{C}$ ) due to interaction with TB can be deduced from Table 1 . We also found complete irreversibility of the denaturing process. This irreversibility of HSA denaturation was confirmed in all samples, which agrees very well with other published results [33]. The DSC curves were fitted to a non-two-state model, because this model provided the best fit results. Increase in temperature and enthalpy of denaturation (Table 1) is compatible with the presence of high affinity sites in the folded conformation of proteins [29]. Unlike the above-mentioned thermostability, a decrease in thermodynamic parameters means the existence of multiple low-affinity binding sites in the unfolded conformations of HSA [34]. We can assume that the native structure of HSA is affected by TB molecules, because thermostability signals stabilizing of the TB/HSA complex formation. However, the increasing thermodynamic parameters (denaturation temperature and enthalpy) measured at one scanning rate do not give clear information about the TB/HSA thermostability. Lemli et al. [35] measured thermodynamic parameters including activation energies of BSA in absence and presence of tilmicosin on depending on three different scan rates and found the decrease of thermodynamic parameters at two scan rates. They concluded that the ligand tilmicosin promotes the thermal denaturation of the protein. As we did not perform our measurements at different scan rates we cannot significantly declare on the binding of TB with protein.

\subsection{Fluorescence Quenching}

Fluorescence spectroscopy is a very frequently used method to investigate the interactions between small molecules and macromolecules including proteins. Prior to fluorescence experiments the UV-VIS absorption spectra of TB (Figure S2), HSA, and TB/HSA complex were taken (not shown). The UV-VIS absorption spectrum of TB shows two strong peaks at 208 and $220 \mathrm{~nm}$ measured at maximal used 
TB concentration (Figure S2). On the contrary, well-known UV-VIS absorption spectrum of HSA is characterized by the strong peak at $210 \mathrm{~nm}$ and the weak peak at $280 \mathrm{~nm}$, which is due to the aromatic acids. Localization of the aromatic acids in the binding sites of HSA macromolecule led to use the wavelength $280 \mathrm{~nm}$ as an excitation wavelength in fluorescence quenching measurements. To separate fluorescence spectra of Tyr and Trp, we used the excitation wavelength $295 \mathrm{~nm}$.

We repeated our preliminary fluorescence quenching experiments at room temperature [28] to confirm and specify the interaction between TB and HSA. The decrease of HSA fluorescence in the absence and presence of TB measured at $25^{\circ} \mathrm{C}$ is shown in Figure 2A. From this figure it can be seen that the intensity of fluorescence of HSA declines with the raising concentration of pesticide, which is due to fluorescence quenching. We observed no shift in maximum emission wavelength of HSA (Figure 2A inset), suggesting that small molecules are likely to interact with HSA via the hydrophobic region located inside the protein [26].
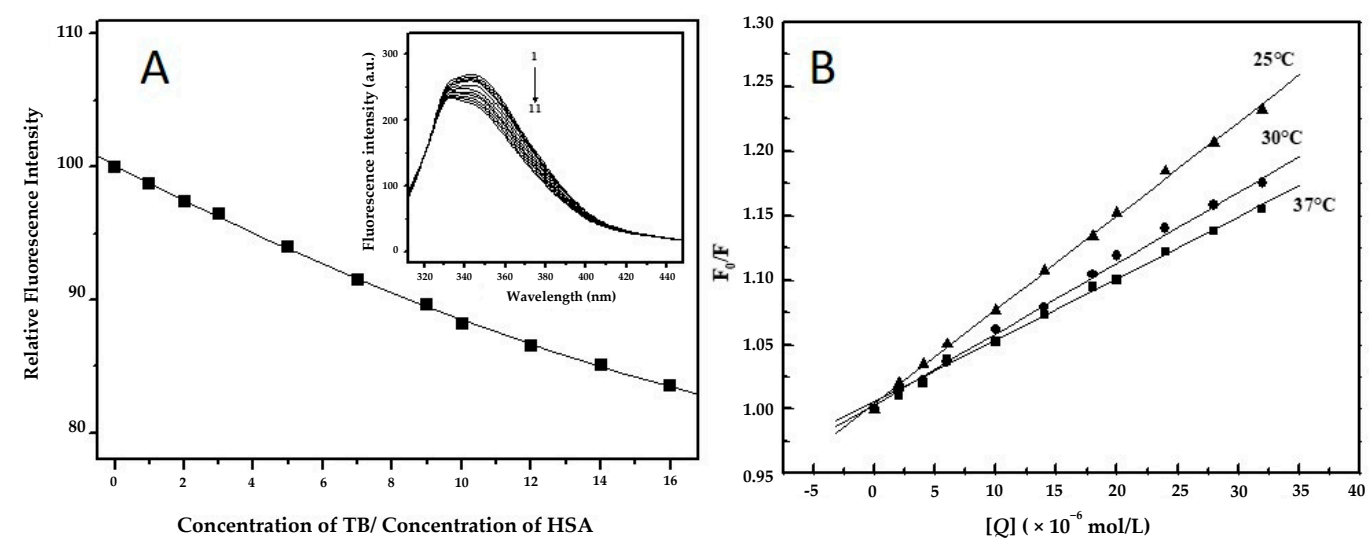

Figure 2. (A) Decrease of HSA fluorescence in the absence and presence of TB. Inset: Fluorescence spectra of TB/HSA complexes; c (HSA) $=2 \times 10^{-6} \mathrm{~mol} / \mathrm{L}, \mathrm{c}(\mathrm{TB})=0-32 \times 10^{-6} \mathrm{~mol} / \mathrm{L}(1-11) ; \lambda_{\mathrm{exc}}=295$ $\mathrm{nm} ; \lambda_{\mathrm{em}}=300-500 \mathrm{~nm} ; \mathrm{pH}=7.4 ; \mathrm{t}=25^{\circ} \mathrm{C}$ [28]. (B) Stern-Volmer plots for the binding of TB with HSA at different temperatures.

The values of $K_{S V}, K_{A}$ and $n$ at $25^{\circ} \mathrm{C}$ have been already published by our group [28]. We realized additional measurements at $30^{\circ} \mathrm{C}$ and $37^{\circ} \mathrm{C}$ to find a temperature dependence of fluorescence quenching [36].

Fluorescence quenching can be induced by processes such as ground state complex formation, excited-state reactions, energy transfers and molecule rearrangements [36]. Generally, the quenching mechanisms are divided as static quenching and dynamic quenching, which can be characterized by their different dependence on temperature [37]. By dynamic quenching, the quenching constants of the fluorescent complexes increase with rising temperature, because dynamic quenching depends primarily on diffusion. On the contrary, by the static quenching, the increase in temperature results in decreased stability of complexes; the values of quenching constants will be lower. The consequence of higher temperature is faster diffusion and broader amounts of collisional quenching and this typically leads to the dissociation of weakly bound complexes [38].

The possible quenching mechanism can be interpreted with the Stern-Volmer Equation (1) [36,39]:

$$
\frac{F_{0}}{F}=1+K_{q} \tau_{0}[Q]=1+K_{S V}[Q]
$$

where $F_{0}$ and $F$ are the intensities of fluorescence of the biomacromolecule before and after addition of quencher (TB), respectively. $K_{q}$ is the quenching rate constant of the biomacromolecule, $\tau_{0}$ is the average lifetime of the fluorescence of biomacromolecule without presence of quencher (about $10 \mathrm{~ns}$ for most of the fluorophores [40], [Q] is the concentration of quencher (TB), and $K_{S V}$ is the Stern-Volmer constant. Figure 2B shows Stern-Volmer plots for fluorescence quenching of the complex TB/HSA at three different temperatures. The corresponding $K_{S V}$ is summarized in Table 2 . The value of $K_{S V}$ is 
inversely correlated with the temperature, implying that the quenching mechanism of HSA by TB is initiated by static quenching.

Table 2. Association constants and thermodynamic parameters for the interaction between HSA and TB.

\begin{tabular}{ccccccc}
\hline $\begin{array}{c}\text { Temperature } \\
\left({ }^{\circ} \mathbf{C}\right)\end{array}$ & $K_{S V}(\mathrm{~L} / \mathbf{m o l})$ & $K_{A}(\mathrm{~L} / \mathbf{m o l})$ & $n$ & $\Delta G(\mathbf{k J} / \mathbf{m o l})$ & $\Delta H(\mathbf{k J} / \mathbf{m o l})$ & $\Delta S(\mathbf{J} / \mathbf{m o l} \cdot \mathbf{K})$ \\
\hline $25^{*}$ & $7.26 \times 10^{3} \pm 0.09$ & $8.51 \times 10^{3} \pm 0.06$ & $1.01 \pm 0.02$ & $-22.68 \pm 0.001$ & $-56.96 \pm 0.02$ & $-115.98 \pm 0.07$ \\
30 & $4.77 \times 10^{3} \pm 0.02$ & $4.85 \times 10^{3} \pm 0.02$ & $0.98 \pm 0.02$ & $-22.10 \pm 0.001$ & & \\
37 & $3.15 \times 10^{3} \pm 0.02$ & $3.46 \times 10^{3} \pm 0.09$ & $0.96 \pm 0.02$ & $-20.99 \pm 0.002$ & & \\
\hline \multicolumn{7}{c}{$*[28]}$.
\end{tabular}

\subsection{Determination of Binding Parameters}

The binding parameters such as number of binding sites $(n)$ and the association constant $\left(K_{A}\right)$ can be estimated from the Hill Equation (2) [41-43]:

$$
\frac{\log \left(F_{0}-F\right)}{F}=\log K_{A}+n \log [Q]
$$

where $\mathrm{F}_{0}$ and $\mathrm{F}$ are the intensities of fluorescence of biomacromolecule before and after addition of quencher $(\mathrm{TB})$ and $[Q]$ is the total quencher concentration. By plotting $\log \left(F_{0}-F\right) / F$ versus $\log [Q]$, the association constant and number of binding sites $n$ can be obtained. Hill plots of TB quenching effect on fluorescence of HSA at the different temperatures are displayed in Figure S3.

The corresponding $K_{A}$ and $n$ are summarized in Table 2. The results show a slight binding affinity between HSA and TB. The number of binding sites $n$ in HSA approximates to one signaling that only one site is reactive to TB in the experimental concentration range.

In comparison, the interaction of four other triazole fungicides (triadimefon, imazalil myclobutanil, penconazole) with HSA has been reported by Zhang et al. [26]. The association constants determined by means of fluorescence quenching in their study range from $3.96 \times 10^{3} \mathrm{~L} / \mathrm{mol}$ (triadimefon) to $8.47 \times 10^{3}$ $\mathrm{L} / \mathrm{mol}$ (penconazole) [26]. Our association constant for TB/HSA complex $\left(8.51 \times 10^{3} \mathrm{~L} / \mathrm{mol}\right)$ approaches those constants very well. The number of binding sites for TB, which is $1.01 \pm 0.02$ (Table 2) corresponds with those obtained by Zhang et al. [26]. Considering the chemical structure of all triazole fungicides, we may assume that both TB and penconazole molecules look similar. This fact can be one of several other reasons explaining their very similar binding affinity expressed in terms of association constants. For comparison, the binding affinities of other pesticides to HSA are reported in the studies by Wang $[24,25]$. They used the spectroscopic approach to find association constants for imidacloprid/HSA and thiacloprid/HSA complexes respectively. Both molecules represent neonicotinoid insecticides currently used in agriculture. Comparing the association constants of triazole and neonicotinoide pesticides, we can declare that the binding affinity to HSA of triazole fungicides including TB to HSA is lower than that of neonicotinoides. However, the differences are not very pronounced.

\subsection{Thermodynamic Parameters}

Interactions between small molecules and biomacromolecules include four types of non-covalent interactions, hydrophobic, hydrogen, van der Waals forces and electrostatic forces. Thermodynamic parameters such as Gibbs free energy change $(\Delta G)$, entropy change $(\Delta S)$ and enthalpy change $(\Delta H)$ can give an indication useful for defining interaction modes [43]. If $\Delta H$ does not change significantly over the temperature range studied, it can be regarded as a constant, and then $\Delta H, \Delta G$ and $\Delta S$ are estimated from the van't Hoff Equation (3):

$$
\ln K_{A}=\frac{-\Delta H}{R T}+\frac{\Delta S}{R}
$$

where $K_{A}$ is the association constant at temperature $T$ and $R$ is the universal gas constant $(R=8.314472$ $\mathrm{J} / \mathrm{K} \cdot \mathrm{mol})$. Van't Hoff plot for the interaction TB and HSA is shown in Figure S4. 
The Gibbs free energy change can be obtained from the Equation (4):

$$
\Delta G=\Delta H-T \Delta S
$$

Previous studies [44,45] have defined the magnitudes and signs of the thermodynamic parameters correlated with various individual kinds of interaction. For $\Delta H<0$ and $\Delta S>0$, the hydrophobic interactions play major role, for $\Delta H<0$ and $\Delta S<0$, van der Waals forces and hydrogen bond formation are suggested as more important, whereas for $\Delta H \approx 0$ and $\Delta S>0$, contributions to these changes are associated with electrostatic forces [46]. The calculated values of $\Delta H, \Delta G$ and $\Delta S$ are summarized in Table 2. The negative values of $\Delta G$ indicate the spontaneous binding process. The values of $\Delta H$ and $\Delta S$ are negative, which indicates that the van der Waals forces or/and hydrogen bonds play a main role in binding process. We assume that this situation is caused by the existence of the OH group in $\mathrm{TB}$, which is the hydrogen bond donor. However, $\mathrm{N}$ atoms, which are located on the triazole ring can very easily form hydrogen bonds with amino acid residues such as Arg and tryptophan (Trp). Besides, $\mathrm{TB}$ contains aromatic rings, and therefore $\pi \rightarrow \pi$ stacking interactions with amino acid residues such as His, Tyr and Trp, in HSA are also reasonable.

\subsection{Synchronous Fluorescence Spectroscopy}

Synchronous fluorescence spectroscopy involves the simultaneous scanning of excitation and the fluorescence monochromators of a fluorimeter, while maintaining a settled wavelength difference ( $\Delta \lambda$, D-values) between them. Synchronous fluorescence spectra are used to study the molecular environment in the vicinity of a fluorophore. The advantages of this method are spectrum simplification, spectral band reduction and prevention of various perturbations [47]. Vekshin [48] suggested a useful method to study the environment of amino acid residues by measuring the possible shift in wavelength emission maximum, especially the shift position of the emission maximum corresponding to changes in polarity around the chromophore molecule.

The emission spectra of HSA come from three kinds of fluorophores, namely Phe, Tyr and Trp, whose fluorescence spectra overlap. When the D-values $(\Delta \lambda)$ between excitation wavelengths and emission wavelengths were settled at $15 \mathrm{~nm}$ and $60 \mathrm{~nm}$, the spectra provided the individual information for amino acids residues Tyr and Trp in the protein, respectively [49]. Several authors [16,50,51] found that in the HSA molecule structure the subdomain IIA contains a large hydrophobic cavity, which prefers to accept bulky heterocyclic anions like TB is. Based on these findings, it can be supposed that the primary binding site of triazole fungicides including TB is likely to be subdomain IIA where Trp214 is only Trp in the HSA molecule.

The fluorescence spectra characteristic of Tyr and Trp residues are shown in Figure S5. It is obvious that the intensities of the Trp residues are stronger than those of Tyr residues. The maximum emission wavelengths remain unchanged during the interaction, suggesting that polarity around amino acids residues Tyr and Trp is unchanged. No significant change was found in the fluorescent emission peak position of both Tyr and Trp residues. Thus, the addition of TB did not rearrange the microenvironment of Tyr and Trp in HSA.

\subsection{Site Markers Competitive Experiments}

To elucidate the binding site of TB to HSA, we made the competitive experiments. The measurements were carried out in the presence of two ligands ketoprofen (KTF) and ibuprofen (IBF). KTF and IBF, nonsteroidal anti-inflammatory drugs, have been identified as stereotypical ligands for Sudlow's sites I and II (subdomain IIA and IIIA), respectively [52].

With the addition of TB to the KTF/HSA and IBF/HSA mixtures, the intensity of fluorescence of HSA gradually decreased (Figures S6 and S7). To comparison of the influence of KTF and IBF on the binding TB to HSA, the association constants in the presence of site markers were calculate from Hill Equation (2) (Table S1). The results show that in the presence of KTF, the association constant 
of TB/HSA complex was very low in comparison to this case when IBF was present in the mixture. So the presence of IBF in the mixture caused only a small change in the binding parameters (Table S1). These results indicate that the bound of TB to HSA was affected by the presence of KTF, while IBF did not prevent the interaction of TB in its usual location. This analysis indicated that the binding site of TB was mainly located within Sudlow site I (subdomain IIA) of HSA. To verify above mentioned results, we used the method originated from Sudlow et al. [53]. This method dealt with probe (KTF, IBF) displacement, which can be expressed by following Equation (5):

$$
\text { Probe displacement }=F_{2} / F_{1}
$$

where $F_{2}$ represents the fluorescence intensity of TB/HSA system in the presence of the probe and $F_{1}$ represents the fluorescence intensity of TB/HSA system in the absence of the probe. As shown on Figure 3 the increasing concentration of ketoprofen led to decreasing of fluorescence intensity of TB/HSA complex. However, the increasing concentration of ibuprofen has a little impact on fluorescence intensity of TB/HSA complex. The displacement of TB bound to HSA after addition of KTF indicated that site I (subdomain IIA) was the probable binding site of TB to HSA.

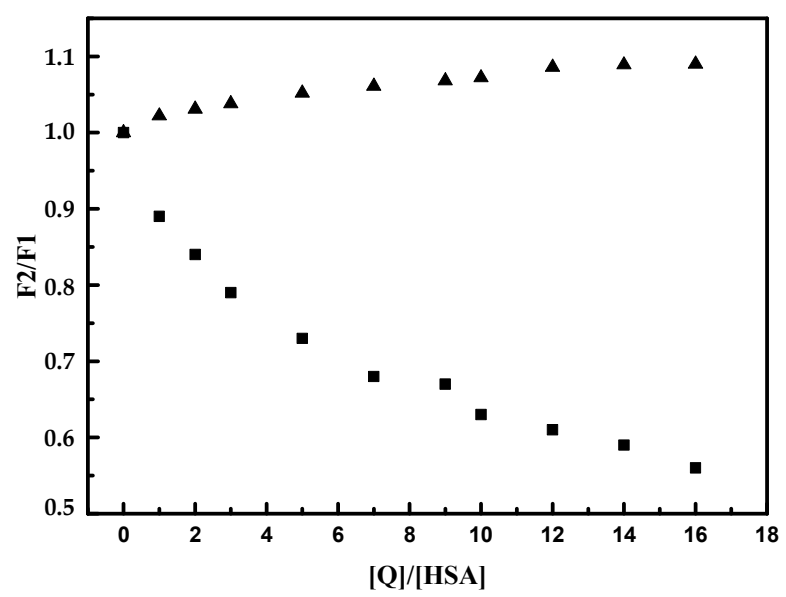

Figure 3. Effect of ketoprofen (KTF) and ibuprofen (IBF) on fluorescence intensity of the TB/HSA system; $\mathrm{c}(\mathrm{TB})=\mathrm{c}(\mathrm{HSA})=2 \times 10^{-6} \mathrm{~mol} / \mathrm{L} ; \mathrm{c}(\mathrm{KTF})=\mathrm{c}(\mathrm{IBF})=0-32 \times 10^{-6} \mathrm{~mol} / \mathrm{L} ;[Q]: \Delta$ ibuprofen ketoprofen; $\mathrm{pH}=7.4 ; \mathrm{t}=25^{\circ} \mathrm{C}$.

\subsection{D Fluorescence Spectroscopy}

To analyze the changes in protein secondary structure after interaction with TB, 3D fluorescence spectroscopy was utilized. 3D fluorescence spectroscopy has been commonly used for studying the interaction between proteins and small molecules in recent years. The fluorescence intensity, emission wavelength and excitation wavelength are the parameters used to investigate the synthetic formation of the samples. In addition, the contour fluorescence spectra can also provide some meaningful information [54,55]. The 3D fluorescence spectra and the contour fluorescence spectra for HSA and TB/HSA are displayed in Figure 4.

Peak a $\left(\lambda_{\text {ex }}=\lambda_{\text {em }}\right)$ is known as the Rayleigh scattering peak, and peak b $\left(2 \lambda_{\text {ex }}=\lambda_{\text {em }}\right)$ is known as the second-order scattering peak, and they arise from elastic light scattering on particles smaller than the wavelength of light. The intensity of both scattering peaks increases with addition of TB resulting in an increase in the diameter of the molecule and thus greater scattering $[55,56]$. Peak $1\left(\lambda_{\text {ex }}=275 \mathrm{~nm}\right.$, $\lambda_{\mathrm{em}}=340 \mathrm{~nm}$ ) represents the intensity of fluorescence of Tyr and Trp amino acid residues involving $\pi \rightarrow \pi^{*}$ transition, reflecting some changes in the tertiary structure. Peak $2\left(\lambda_{\text {ex }}=230 \mathrm{~nm}, \lambda_{\mathrm{em}}=330 \mathrm{~nm}\right)$ is mainly caused by $n \rightarrow \pi^{*}$ transition of protein polypeptide backbone structures and signifies changes in the secondary structure of HSA $[26,57]$. 

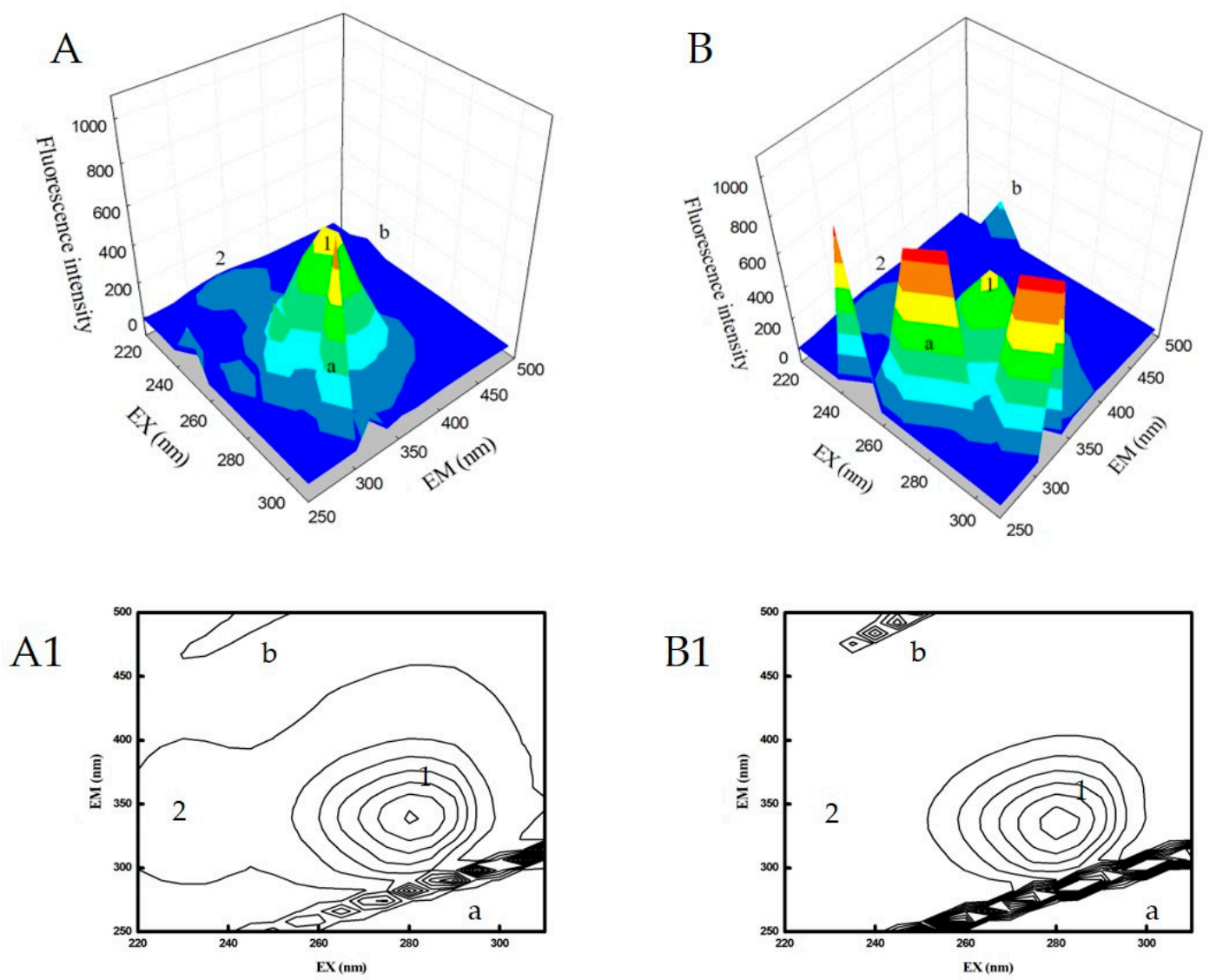

Figure 4. 3D fluorescence spectra of HSA in the absence (A, A1) and in the presence of TB (B, B1). $\mathrm{c}(\mathrm{HSA})=2 \times 10^{-6} \mathrm{~mol} / \mathrm{L} ; \mathrm{c}(\mathrm{TB})=32 \times 10^{-6} \mathrm{~mol} / \mathrm{L} ; \mathrm{pH}=7.4 ; \mathrm{t}=25^{\circ} \mathrm{C}$.

From the figures it can be seen that the fluorescence emission intensity of peak 1 decreased upon the addition of TB. Similarly, the fluorescence of peak 2 also decreased, which implies that interaction with TB possibly caused some minor changes in stabilization of HSA and a slight unfolding of its polypeptide backbone, resulting in conformational changes. The intensities of the measured peaks are summarized in Table S2.

\subsection{Circular Dichroism}

To collect more information on the binding of TB to HSA, circular dichroism spectroscopy was applied to investigation the secondary structure of HSA and TB/HSA complex. CD is a sensitive technique for monitoring conformational changes in proteins. HSA presents two negative bands in the ultraviolet region at 208 and $222 \mathrm{~nm}$, characteristic for the $\alpha$-helical structure [58,59]. These two peaks contribute to $\pi \rightarrow \pi^{*}$ transfer $(208 \mathrm{~nm})$ and $n \rightarrow \pi^{*}$ transfer $(222 \mathrm{~nm})$ for the peptide bond in the $\alpha$-helix [60]. CD measurements performed in the absence and in the presence of different concentrations of TB displayed that the binding of TB to HSA caused a slight decrease in both bands (Figure S8). The CD results were expressed in terms of mean residue ellipticity (MRE), according to the following Equation (6):

$$
\mathrm{MRE}=\frac{\text { Observed } \mathrm{CD}(\mathrm{mdeg})}{10 \mathrm{cnl}}
$$

where $c$ is the concentration of HSA, $n$ is the number of amino acid residues of HSA and $l$ is the path length. 
The $\alpha$-helix contents of free HSA and TB/HSA complexes were calculated from MRE values at $208 \mathrm{~nm}$ using the following Equation (7) [61]:

$$
\alpha-\operatorname{helix}(\%)=\frac{-\mathrm{MRE}_{208 \mathrm{~nm}}-4000}{33000-4000} \times 100
$$

Free HSA contains $55.75 \% \alpha$-helical structures, and in the presence of TB the content of $\alpha$-helical structures gradually decreases to $53.23 \%$ at a molar ratio of $5 / 1$. We also used ethanol to probe its effect on secondary structure of HSA. The effect of ethanol was less than $1 \%$, so we can state that TB causes slight changes in the secondary structure of HSA.

This result shows that TB interacts with the amino acid residues of the polypeptide backbone in HSA, disrupts the hydrogen bonds [26], and evokes protein destabilization [62,63]. The CD spectra in the absence and in the presence of TB have similar shape, without any changes of peak positions, which indicates that the $\alpha$-helical structure is still dominant. All these results reveal that the binding of TB could induce slight conformational changes in HSA, which is in good agreement with the previous results of 3D fluorescence spectroscopy.

\subsection{Molecular Docking}

The crystal structure of HSA (variant 1AO6) was used as the target for docking. Blind docking search resulted in finding one of the IBF binding sites (Arg209 and Glu354) and the warfarin binding site (Arg218 and Lys195). In further simulations we reduced the search space to a volume of size $30 \times$ $30 \times 30 \AA$ centered on the warfarin binding site and the IBF binding sites.

The most stable binding in the warfarin cavity was docked with binding energy of $-29.28 \mathrm{KJ} / \mathrm{mol}$ with error of computation being $\pm 11.51 \mathrm{KJ} / \mathrm{mol}$ [64]. This is in agreement with the experimental measurements. The conformation is displayed in Figure 5A with its respective electrostatic potential in Figure 5B. The amino acids that are surrounding it are: Trp214, Ala215, Arg218, Leu219, Arg222, Leu238, His242, Leu260, Ala261, Ile-64, Ile290 and Ala291.
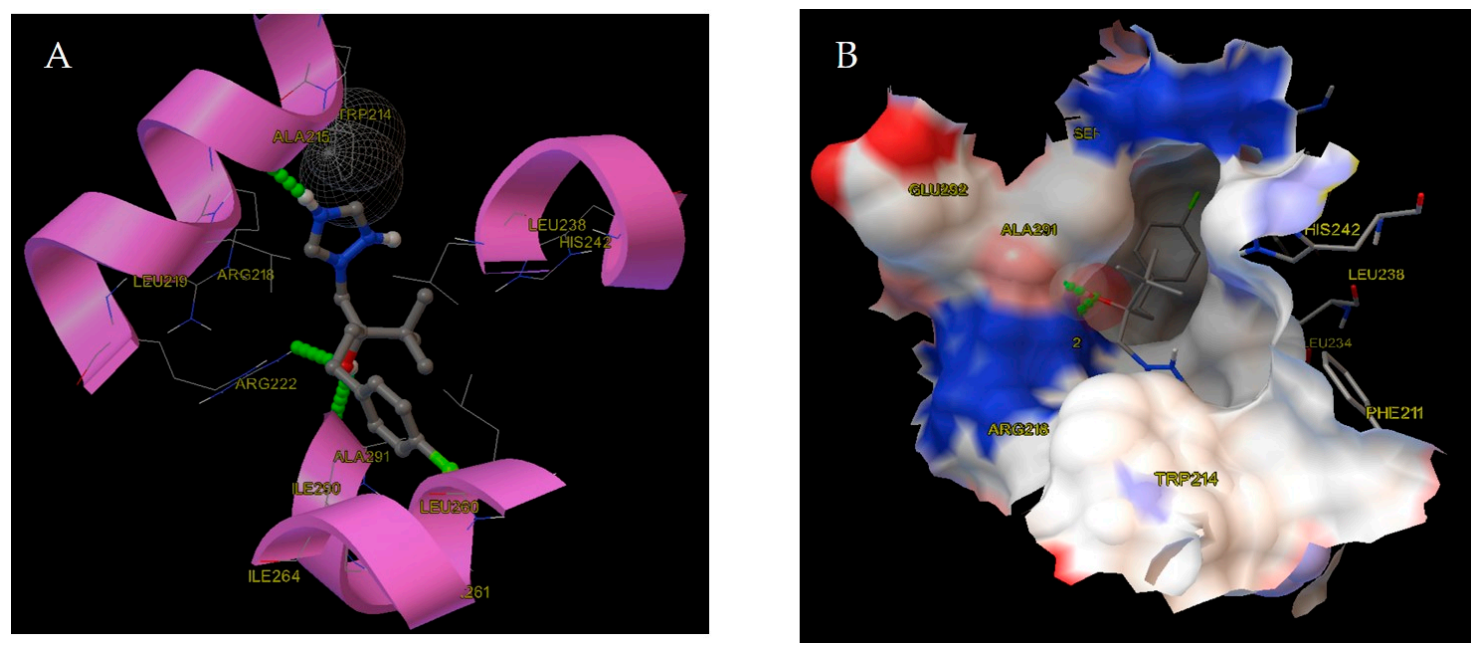

Figure 5. (A) Binding mode of TB to HSA. The secondary structure of the protein is shown and the neighboring amino acid residues are labeled. The hydrogen bonds are indicated by green lines. (B) Electrostatic potential of the ligand binding pocket in subdomain IIA (site I) of HSA. The negative and positive electrostatic potentials are colored red and blue, respectively.

After further investigation of the electrostatic potential of the binding pocket, we deduced that the pocket is slightly positively charged and thus can interact with the negatively-charged apexes of TB (mainly the triazole ring, $\mathrm{Cl}^{-}$locus and the hydroxyl group). For TB three hydrogen bonds were predicted from the conformation, as follows: the oxygen atom of the hydroxyl group receives the 
hydrogen from Arg222, the nitrogen atom of the triazole ring donates the hydrogen to the bond with Ala215, and the edge hydrogen of the hydroxyl group is donated to the bond with Ala291.

It is known that IBF has multiple HSA binding sites [65]. Because these interactions were outside of the scope of this study, we prioritized the two binding sites described in the protein 2BXG [66]. One is in the region of Arg209 and the other Tyr411. The simulations at these sites revealed the existence of stable binding modes with significant binding energies of $-26.77 \mathrm{KJ} / \mathrm{mol}$ and $-29.70 \mathrm{KJ} / \mathrm{mol}$. This was, however, contrary to the results from the experiment where we did not observe any competition between binding of TB and IBF. We speculate that the reason for this is because these two specific sites have a region of highly negative electrostatic potential (Figure S9A,B) generated by the negatively charged residues Arg410, Lys413, Lys541 and Lys545 (Gly207, Arg209, Lys212, Lys323). The negatively charged $\mathrm{Cl}^{-}$end of TB is unable to navigate these electrostatic fields. Unfortunately, AutoDockVina is evaluating individual conformations and not the possibility of reaching such conformations by taking some possible trajectory. Further study using molecular simulations could provide answers to this behavior.

In our simulation we also investigated various other known locations [67] like the Lys525, Lys199, Lys233, Cys34 and others. These simulations did not uncover any significant binding activity. From this point of view, we hypothesize that the main binding activity is happening at the warfarin binding site.

\section{Materials and Methods}

\subsection{Chemicals and Reagents}

TB (CAS Number 107534-96-3) was obtained from Sigma Aldrich, Darmstadt, Germany, with the purity $\geq 98.4 \%$. TB was dissolved in spectroscopic grade $100 \%$ ethanol at concentration $10^{-3} \mathrm{~mol} / \mathrm{L}$. HSA (fatty acid-free, globulin-free, purity no less than 99\%) was purchased from Sigma Aldrich, Darmstadt, Germany, and was used without further purification. a stock solution of HSA (concentration $\left.5 \times 10^{-4} \mathrm{~mol} / \mathrm{L}\right)$ was prepared in Tris- $\mathrm{HCl}(0.05 \mathrm{~mol} / \mathrm{L}$ Tris $+0.1 \mathrm{~mol} / \mathrm{L} \mathrm{NaCl})$ buffer, $\mathrm{pH} 7.4$ and conserved in the dark at $4{ }^{\circ} \mathrm{C}$. Ketoprofen (KTF) and ibuprofen (IBF) were obtained from Sigma Aldrich, Darmstadt, Germany, with purity $\geq 98.0 \%$. KTF and IBF were dissolved in $100 \%$ ethanol at the concentration $10^{-3} \mathrm{~mol} / \mathrm{L}$. Phosphate buffer $(0.02 \mathrm{~mol} / \mathrm{L}, \mathrm{pH} 7.4)$ was used for DSC calorimetric and CD spectroscopic measurements. Tris(hydroxymethyl)aminomethane, $\mathrm{NaCl}, \mathrm{HCl}$, and other reagents were all of high purity. The buffers were prepared in the triple distilled water. All experiments were realized from 3 to 8 (fluorescence quenching and CD) times independently and presented data were summarized as the mean with the related standard deviation.

\subsection{Differential Scanning Calorimetry}

Differential scanning calorimetry measurements were performed on a Microcal VP-Capillary automated high-sensitivity differential calorimeter (Malvern Panalytical, Malvern, Worcestershire, UK) in the range of temperature from 25 to $95{ }^{\circ} \mathrm{C}$ at specific heating rate $1.5^{\circ} \mathrm{C} / \mathrm{min}$. The concentration of HSA was fixed at $3 \times 10^{-5} \mathrm{~mol} / \mathrm{L}$. The concentration of TB was subsequently varied within the range $3 \times$ $10^{-5}-3 \times 10^{-4} \mathrm{~mol} / \mathrm{L}$. DSC curves and chemical kinetic data were obtained using DSC thermoanalytical software (Version 8.0, OriginLab, Northampton, MA, USA).

\subsection{Fluorescence Measurements}

Fluorescence experiments were taken out with the RF 5301 PC spectrofluorimeter (Shimadzu, Kyoto, Japan) equipped with a $1 \mathrm{~cm}$ quartz cell. Excitation wavelength was set at $295 \mathrm{~nm}$ and fluorescence was collected in 300-500 nm emission wavelengths using $5 \mathrm{~nm} / 5 \mathrm{~nm}$ slits. TB/HSA complexes for fluorescence spectroscopy were prepared by titration of TB into $2 \times 10^{-6} \mathrm{~mol} / \mathrm{L}$ HSA to achieve a final concentration of TB from $2 \times 10^{-6} \mathrm{~mol} / \mathrm{L}$ to $32 \times 10^{-6} \mathrm{~mol} / \mathrm{L}$. After each titration the sample was $10 \mathrm{~min}$ stabilized. Decrease of the protein concentration by adding the TB in ethanol was minimal and did not reach $1.5 \%$. All experiments were measured at three different temperatures, 
namely 25,30 and $37^{\circ} \mathrm{C}$. The inner filter effect was eliminated by using very low concentration of HSA, which gives the absorbance less than 0.1 at excitation wavelength $295 \mathrm{~nm}$.

Synchronous fluorescence spectra were recorded at room temperature. The interval of scanning between excitation and emission wavelength was fixed at 15 and $60 \mathrm{~nm}$, respectively, and the emission was recorded from 200 to $400 \mathrm{~nm}$.

Site markers competitive experiments were recorded at room temperature. The excitation wavelength was set at $295 \mathrm{~nm}$ and the emission was collect in the range $300-500 \mathrm{~nm}$ using $5 \mathrm{~nm} / 5 \mathrm{~nm}$ slits. The concentrations of KTF, IBF and HSA were fixed at $2 \times 10^{-6} \mathrm{~mol} / \mathrm{L}$. TB was then gradually added into KTF/HSA and IBF/HSA complexes. The 3D fluorescence spectra were also recorded at room temperature. The initial excitation wavelength was set at $220 \mathrm{~nm}$ with increments of $5 \mathrm{~nm}$, and the emission was collected from 250 to $500 \mathrm{~nm}$.

The different values of HSA concentrations were customized to the optimal conditions of the measurement methods used.

\subsection{Circular Dichroism (CD) Studies}

Far-UV CD spectroscopy experiments were recorded on a Jasco J-815 CD spectrometer (Jasco, Easton, MD, USA) equipped with a $0.1 \mathrm{~cm}$ quartz cell. at room temperature and with constant nitrogen flush. The CD spectra of HSA in the presence of TB were recorded from 190 to $270 \mathrm{~nm}$ and scan rate was $50 \mathrm{~nm} / \mathrm{min}$. Three scans were collected for each spectrum, taking the averages as the final data.

TB/HSA complexes for CD spectroscopy were prepared by titration of TB into $3 \times 10^{-6} \mathrm{~mol} / \mathrm{L}$ HSA to achieve a final concentration of TB from $3 \times 10^{-6} \mathrm{~mol} / \mathrm{L}$ to $1.5 \times 10^{-5} \mathrm{~mol} / \mathrm{L}$. Tris- $\mathrm{HCl}$ buffer was exchanged for phosphate buffer $(0.02 \mathrm{~mol} / \mathrm{L}, \mathrm{pH} 7.4)$ to eliminate the influence of $\mathrm{Cl}^{-}$ions.

\subsection{Molecular Docking}

For our investigation we have used the HSA crystallographic data from the Brookhaven Protein Data Bank. The selected species was 1AO6 [67] as it describes HSA in its unbound state with sufficient precision. The molecular structure of TB was taken from PubChem database, entry 86102. For docking we used AutoDockVina [64]. We first performed blind docking for initial interaction site targeting. In the investigation we also included other binding sites that have been mentioned in literature [68]. Our main focus was on investigating TB activity in warfarin binding site.

\section{Conclusions}

Better understanding of the interaction of TB and other fungicides with various possible molecular and/or cellular targets is essential for the determination of their function in biological systems. The present paper focuses on results obtained in the study of TB associations with serum albumins represented by HSA.

In this study we investigated the interaction of triazole fungicide TB with HSA using calorimetric and spectroscopic methods, complemented with theoretical molecular modeling. As shown, TB interacts with HSA in vitro under simulated physiological conditions. The HSA fluorescence quenching by TB is, within the range of experimental concentration, attributed to a static mechanism. The thermodynamic parameters offer proof of structurally related binding modes, which are in good agreement with our molecular modeling results. The displacement of TB from HSA after addition of KTF indicated that Sudlow site I (subdomain IIA) was the probable binding site of TB to HSA. Furthermore, the binding of TB to HSA leads to slight conformational changes in HSA as corroborated by our 3D fluorescence and $\mathrm{CD}$ measurements outcomes.

Our results are also in good agreement with those of Zhang et al. [26], where slight binding interactions and small changes in the secondary structure of HSA after binding with triazole fungicides are reported. 
Supplementary Materials: The Supplementary Materials are available online. Figure S1: DSC curves of HSA, Figure S2: Absorption spectra of TB, Figure S3: Hill plots of TB quenching effect on HSA fluorescence at the different temperatures, Figure S4: Van't Hoff plot for the interaction between TB and HSA, Figure S5: Synchronous fluorescence spectra of HSA, Figure S6: Effect of site marker KTF to the TB/HSA system, Figure S7: Effect of site marker IBF to the TB/HSA system, Figure S8: CD spectra of HSA and TB/HAS, Figure S9: Electrostatic potential of the ligand binding pocket in site II, Table S1: Association constants of competitive experiments for the interaction between TB and HAS, Table S2: Peak position and intensity of fluorescence parameters for the interaction between HSA and TB.

Author Contributions: Conceptualization, J.S. and V.V.; methodology, J.S., V.V., K.Ž., S.H. and J.U.; software, J.U., S.H. and K.Ž.; validation, J.S. and J.U.; formal analysis, S.H.; investigation, K.Ž., S.H. and V.V.; resources, V.V., K.Ž. and S.H.; data curation, J.S., B.H. and J.U.; writing-original draft preparation, K.Ž. and S.H.; writing-review and editing, J.S., J.U., and B.H.; visualization, V.V., K.Ž. and S.H.; supervision, J.S., J.U. and B.H.; project administration, J.S. and V.V.; funding acquisition, J.S., J.U. and B.H.

Funding: This paper is the result of implementation of the project entitled Medical University Science Park in Košice (MediPark, Košice-Phase II) ITMS2014+ 313011D103, supported by the Operational Programme Research \& Innovation, funded by the ERDF. This work was also supported with grants from the Slovak Research Grant Agency VEGA No. 1/0242/19 and KEGA No. 012 UVLF-4/2018.

Acknowledgments: The authors would like to thank the colleagues from the Centre of Interdisciplinary Biosciences and the Department of Biophysics at Slovak Academy of Sciences (Košice, Slovakia) for the possibility to realize DSC and CD experiments.

Conflicts of Interest: The authors declare no conflicts of interest.

\section{References}

1. Clausen, C.A.; Yang, V. Protecting wood from mould, decay, and termites with multi-component biocide systems. Int. Biodeterior. Biodegrad. 2007, 59, 20-24. [CrossRef]

2. Fera, M.T.; La camera, E.; Desarro, A. New triazoles and echinocandins: Mode of action, in itro activity and mechanisms of resistance. Expert Rev. Anti-infect. Ther. 2009, 7, 981-998. [CrossRef] [PubMed]

3. U.S. Environmental Protection Agency. Available online: https://www.epa.gov/pesticide-science-andassessing-pesticide-risks/evaluating-pesticides-carcinogenic-potential\#a (accessed on 10 January 2014).

4. EFSA. Available online: https://www.efsa.europa.eu/en/efsajournal/pub/3485 (accessed on 3 January 2014).

5. Muñoz-Leoz, B.; Ruiz-Romera, E.; Antigüedad, I.; Garbisu, C. Tebuconazole application decreases soil microbial biomass and activity. Soil Biol. Biochem. 2011, 43, 2176-2183. [CrossRef]

6. Bayer crop science limited. Environmental information sheet FolicurßMAPP number 11278. Available online: https://voluntaryinitiative.org.uk/media/1379/folicur-version-3-guideline-version-4.pdf (accessed on 15 February 2015).

7. Montuelle, B.; Dorigo, U.; Bérard, A.; Volat, B.; Bouchez, A.; Tlili, A.; Gouy, S.; Pesce, S. The periphyton as a multimetricbioindicator for assessing the impact of land use on rivers: An overview of the Ardières-Morcille experimental watershed (France). In Global Change and River Ecosystems-Implications for Structure, Function and Ecosystem Services; Stevenson, R.J., Sabater, S., Eds.; Springer: Dordrecht, the Netherlands, 2010; pp. 123-141.

8. Elsaesser, D.; Schulz, R. Mitigation of fungicide pollution in vegetated agricultural surface waters: GIS modelling and monitoring in the field. In Proceedings of the SETAC Europe 18th Annual Meeting, Warsaw, Poland, 25-29 May 2008; pp. 406-407.

9. Yu, L.; Chen, M.; Liu, Y.; Gui, W.; Zhu, G. Thyroid endocrine disruption in zebrafish larvae following exposure to hexaconazole and tebuconazole. Aquat. Toxicol. 2013, 138, 35-42. [CrossRef] [PubMed]

10. Holečková, B.; Šiviková, K.; Dianovský, J.; Galdíková, M. Effect of triazole pesticide formulation on bovine culture cells. J. Environ. Sci. Health B 2013, 48, 1080-1088. [CrossRef] [PubMed]

11. Fustinoni, S.; Polledri, E.; Mercadante, R.; Rubino, F.M.; Colosio, C.; Moretto, A. Time course of excretion of tebuconazole and its metabolites in vineyard workers. G. Ital. Med. Lav. 2012, 34, 423-424.

12. Schummer, C.; Salquebre, G.; Briand, O.; Millet, M.; Appenzeller, B.M. Determination of farm workers' exposure to pesticides by hair analysis. Toxicol. Lett. 2012, 210, 203-210. [CrossRef]

13. Mas, N.; Galiana, I.; Hurtado, S.; Mondragón, L.; Bernardos, A.; Sancenón, F.; Murguía, J.R. Enhanced antifungal efficacy of tebuconazole using gated ph-driven mesoporous nanoparticles. Int. J. Nanomed. 2014, 9, 2597. 
14. Monkos, K. On the hydrodynamics and temperature dependence of the solution conformation of human serum albumin from viscometry approach. Biochim. Biophys. Acta 2004, 1700, 27-34. [CrossRef]

15. Peters, T.J. The albumin molecule: Its structure and chemical properties. In All about Albumin: Biochemistry, Genetics and Medical Applications; Peters, T.J., Ed.; Academic Press: San Diego, CA, USA, 1996; pp. 9-75.

16. Fehske, K.J.; Muller, W.E.; Wollert, U. The location of drug binding sites in human serum albumin. Biochem. Pharmacol. 1981, 30, 687-692. [CrossRef]

17. Kragh-Hansen, U. Molecular aspects of ligand binding to serum albumin. Pharmacol. Rev. 1981, 33, 17-53. [PubMed]

18. Putnam, F.W.; Lozier, J.; Takahashi, N. Complete amino acid sequence of human plasma beta 2-glycoprotein I. Proc. Natl. Acad. Sci. USA 1984, 81, 3640-3644.

19. Miškovský, P. Hypericin-A new antiviral and antitumor photosensitizer: Mechanism of action and interaction with biological macromolecules. Curr. Drug Targets 2002, 3, 55-84. [CrossRef] [PubMed]

20. Fabriciová, G.; Sanchez-Cortes, S.; Garcia-Ramos, J.V.; Miškovský, P. Surface-enhanced Raman spectroscopy study of the interaction of the antitumoral drug emodin with human serum albumin. Biopolymers 2004, 74, 125-130. [CrossRef] [PubMed]

21. Silva, D.; Cortez, C.M.; Cunha-Bastos, J.; Louro, S.R. Methyl parathion interaction with human and bovine serum albumin. Toxicol. Lett. 2004, 147, 53-61. [CrossRef] [PubMed]

22. Cui, Y.; Guo, J.; Xu, B.; Chen, Z. Binding of chlorpyrifos and cypermethrin to blood proteins. Pestic. Biochem. Physiol. 2006, 85, 110-114. [CrossRef]

23. Yan, C.N.; Mei, P.; Gua, Z.J.; Liu, Y. Studies on thermodynamics features of the interaction between imidacloprid and bovine serum albumin. Chin. J. Chem. 2007, 25, 1085-1089. [CrossRef]

24. Wang, Y.Q.; Tang, B.P.; Zhang, H.M.; Zhou, Q.H.; Zhang, G.C. Studies on the interaction between imidacloprid and human serum albumin: Spectroscopic approach. J. Photochem. Photobiol. B 2009, 94, 183-190. [CrossRef]

25. Wang, Y.; Wang, X.; Wang, J.; Zhao, Y.; He, W.; Guo, Z. Noncovalent interactions between a trinuclearmonofunctional platinum complex and human serum albumin. Inorg. Chem. 2011, 50, 12661-12668. [CrossRef]

26. Zhang, J.; Zhuang, S.; Tong, C.; Liu, W. Probing the molecular interaction of triazole fungicides with human serum albumin by multispectroscopic techniques and molecular modeling. J. Agric. Food Chem. 2013, 61, 7203-7211. [CrossRef]

27. Sułkowska, A.; Maciążek-Jurczyk, M.; Bojko, B.; Rownicka, J.; Zubik-Skupień, I.; Temba, E.; Sułkowski, W.W. Competitive binding of phenylbutazone and colchicine to serum albumin in multidrug therapy: a spectroscopic study. J. Mol. Struct. 2008, 881, 97-106. [CrossRef]

28. Staničová, J.; Želonková, K.; Verebová, V.; Holečková, B.; Dianovský, J. Interaction of the Fungicide Tebuconazole with Human Serum Albumin: a Preliminary Study. Folia Veterinaria 2018, 62, 85-91. [CrossRef]

29. Shrake, A.; Ross, P.D. Ligand-induced biphasic protein denaturation. J. Biol. Chem. 1990, 265, 5055-5059. [PubMed]

30. Faroongsarng, D. Assessment of the dissociation energetics of some selected ligand drugs bound on human serum albumin by differential scanning calorimetry. AAPS PharmSciTech 2016, 17, 474-481. [CrossRef] [PubMed]

31. Celej, M.S.; Dassie, S.A.; González, M.; Bianconi, M.L.; Fidelio, G.D. Differential scanning calorimetry as a tool to estimate binding parameters in multiligand binding proteins. Anal. Biochem. 2006, 350, 277-284. [CrossRef] [PubMed]

32. Koslen, M.M.; Eskew, M.W.; Pinkert, V.; Hoang, H.; Manyanga, F.; Dean, W.L.; Benight, A.S. Capture Reagent and Strategy for Retrieving Albumin-Bound Ligands from Plasma. Adv. Biol. Chem. 2019, 9, 110-134. [CrossRef]

33. Michnik, A.; Michalik, K.; Kluczewska, A.; Drzazga, Z. Comparative DSC study of human and bovine serum albumin. J. Therm. Anal. Calorim. 2005, 84, 113-117. [CrossRef]

34. Shrake, A.; Ross, P.D. Origins and consequences of ligand-induced multiphasic thermal protein denaturation. Biopolymers 1992, 32, 925-940. [CrossRef]

35. Lemli, B.; Derdák, D.; Laczay, P.; Kovács, D.; Kunsági-Máté, S. Noncovalent Interaction of Tilmicosin with Bovine Serum Albumin. Molecules 2018, 23, 1915. [CrossRef]

36. Lakowicz, J.R. Quenching of fluorescence. In Principles of Fluorescence Spectroscopy., 3rd ed.; Lakowicz, J.R., Ed.; Plenum Press: New York, NY, USA, 1983; pp. 199-227. 
37. Zhang, G.; Wang, L.; Pan, J. Probing the binding of the flavonoid diosmetin to human serum albumin by multispectroscopic techniques. J. Agric. Food Chem. 2012, 60, 2721-2729. [CrossRef]

38. Lu, Y.; Feng, Q.; Cui, F.; Xing, W.; Zhang, G.; Yao, X. Interaction of 3-azido-3-deamino daunorubicin with human serum albumin: Investigation by fluorescence spectroscopy and molecular modelling methods. Bioorg. Med. Chem. Lett. 2010, 20, 6899-6904. [CrossRef] [PubMed]

39. Eftink, M.R.; Ghiron, C.A. Fluorescence quenching studies with proteins. Anal. Biochem. 1981, 114, $199-227$. [CrossRef]

40. Lakowicz, J.R.; Weber, G. Quenching of fluorescence by oxygen. Probe for structural fluctuations in macromolecules. Biochemistry 1973, 12, 4161-4170. [CrossRef] [PubMed]

41. Jiang, M.; Xie, M.-X.; Zheng, D.; Liu, Y.; Li, X.-Y.; Chen, X. Spectroscopic studies on the interaction of cinnamic acid and its hydroxyl derivatives with human serum albumin. J. Mol. Struct. 2004, 692, 71-80.

42. Huang, Y.; Zhang, Z.; Zhang, D.; Lv, J. Flow-injection analysis chemiluminescence detection combined with microdialysis sampling for studying protein binding of drug. Talanta 2001, 53, 835-841. [CrossRef]

43. Tian, J.; Liu, J.; He, W.; Hu, Z.; Yao, X.; Chen, X. Probing the binding of scutellarin to human serum albumin by circular dichroism, fluorescence spectroscopy, FTIR, and molecular modelling method. Biomacromolecules 2004, 5, 1956-1961. [CrossRef] [PubMed]

44. Ross, P.D.; Subramanian, S. Thermodynamics of protein association reactions: Forces contributing to stability. Biochemistry 1981, 20, 3096-3102. [CrossRef] [PubMed]

45. Némethy, G.; Scheraga, H.A. The structure of water and hydrophobic bonding in proteins. iii. The thermodynamic properties of hydrophobic bonds in proteins1, 2. J. Phys. Chem. A 1962, 66, 1773-1789. [CrossRef]

46. Pan, X.; Qin, P.; Liu, R.; Wang, J. Characterizing the interaction between tartrazine and two serum albumins by a hybrid spectroscopic approach. J. Agric. Food Chem. 2011, 59, 6650-6656. [CrossRef] [PubMed]

47. Xiang, G.; Tong, C.; Lin, H. Nitroaniline isomers interaction with bovine serum albumin and toxicological implications. J. Fluoresc. 2007, 17, 512-521. [CrossRef] [PubMed]

48. Vekshin, N.L. Division of tyrosine and tryptophan fluorescent components by synchronous scanning method. Biofizika 1996, 41, 1176-1179. [PubMed]

49. Congdon, R.W.; Muth, G.W.; Splittgerber, A.G. The binding interaction of Coomassie blue with proteins. Anal. Biochem. 1993, 213, 407-413. [CrossRef] [PubMed]

50. Deeb, O.; Rosales-Hernández, M.C.; Gómez-Castro, C.; Garduno-Juárez, R.; Correa-Basurto, J. Exploration of human serum albumin binding sites by docking and molecular dynamics flexible ligand-protein interactions. Biopolymers 2010, 93, 161-170. [CrossRef] [PubMed]

51. He, X.M.; Carter, D.C. Atomic structure and chemistry of human serum albumin. Nature 1992, $358,209$. [CrossRef] [PubMed]

52. Xu, T.; Guo, X.; Zhang, L.; Pan, F.; Lv, J.; Zhang, Y.; Jin, H. Multiple spectroscopic studies on the interaction between olaquindox, a feed additive, and bovine serum albumin. Food Chem. Toxicol. 2012, 50, 2540-2546. [CrossRef] [PubMed]

53. Sudlow, G.; Birkett, D.J.; Wade, D.N. Spectroscopic techniques in the study of protein binding. a fluorescence technique for the evaluation of the albumin binding and displacement of warfarin and warfarin-alcohol. Clin. Exp. Pharmacol. Physiol. 1975, 2, 129-140. [CrossRef] [PubMed]

54. Rodriguez-Cuesta, M.J.; Boqué, R.; Rius, F.X.; Zamora, D.P.; Galera, M.M.; Frenich, A.G. Determination of carbendazim, fuberidazole and thiabendazole by three-dimensional excitation-emission matrix fluorescence and parallel factor analysis. Anal. Chim. Acta 2003, 491, 47-56. [CrossRef]

55. Trevisan, M.G.; Poppi, R.J. Determination of doxorubicin in human plasma by excitation-emission matrix fluorescence and multi-way analysis. Anal. Chim. Acta 2003, 493, 69-81. [CrossRef]

56. Kalaiarasi, G.; Rajkumar, S.R.J.; Dharani, S.; Malecko, J.G.; Prabhakaran, R. An investigation on 3-acetyl-7-methoxy-coumarin Schiff bases and their $\mathrm{Ru}$ (II) metallates with potent antiproliferative activity and enhanced LDH and NO release. RSC Adv. 2018, 8, 1539-1561. [CrossRef]

57. Tian, F.F.; Jiang, F.L.; Han, X.L.; Xiang, C.; Ge, Y.S.; Li, J.H.; Zhang, Y.; Li, R.; Ding, X.L.; Liu, Y. Synthesis of a novel hydrazone derivative and biophysical studies of its interactions with bovine serum albumin by spectroscopic, electrochemical, and molecular docking methods. J. Phys. Chem. B 2010, 114, 14842-14853. [CrossRef] 
58. He, Y.; Wang, Y.; Tang, L.; Liu, H.; Chen, W.; Zheng, Z.; Zou, G. Binding of puerarin to human serum albumin: a spectroscopic analysis and molecular docking. J. Fluoresc. 2008, 18, 433-442. [CrossRef] [PubMed]

59. Kandagal, P.B.; Ashoka, S.; Seetharamappa, J.; Shaikh, S.M.T.; Jadegoud, Y.; Ijare, O.B. Study of the interaction of an anticancer drug with human and bovine serum albumin: Spectroscopic approach. J. Pharm. Biomed. Anal. 2006, 41, 393-399. [CrossRef] [PubMed]

60. Yang, P.; Gao, F. The principle of bioinorganic chemistry; Science Press: Beijing, China, 2002; p. 349.

61. Lu, Z.X.; Cui, T.; Shi, Q.L. Applications of circular dichroism and optical rotatory dispersion in molecular biology; Science Press: Beijing, China, 1987; pp. 79-82.

62. Ding, F.; Diao, J.X.; Sun, Y.; Sun, Y. Bioevaluation of human serum albumin-hesperidin bioconjugate: Insight into protein vector function and conformation. J. Agric. Food Chem. 2012, 60, 7218-7228. [CrossRef] [PubMed]

63. Greenfield, N.J. Using circular dichroism spectra to estimate protein secondary structure. Nat. Protoc. 2006, 1, 2876. [CrossRef] [PubMed]

64. Trott, O.; Olson, A.J. AutoDockVina: Improving the speed and accuracy of docking with a new scoring function, efficient optimization, and multithreading. J.comput.chem. 2010, 31, 455-461. [PubMed]

65. Evoli, S.; Mobley, D.L.; Guzzi, R.; Rizzuti, B. Multiple binding modes of ibuprofen in human serum albumin identified by absolute binding free energy calculations. Phys. Chem. Chem. Phys. 2016, 18, 32358-32368. [CrossRef] [PubMed]

66. Ghuman, J.; Zunszain, P.A.; Petitpas, I.; Bhattacharya, A.A.; Otagiri, M.; Curry, S. Structural basis of the drug-binding specificity of human serum albumin. J. Mol. Biol. 2005, 353, 38-52. [CrossRef] [PubMed]

67. Sugio, S.; Kashima, A.; Mochizuki, S.; Noda, M.; Kobayashi, K. Crystal structure of human serum albumin at $2.5 \AA$ A resolution. Protein Eng. 1999, 12, 439-446. [CrossRef]

68. Lee, P.; Wu, X. Modifications of human serum albumin and their binding effect. Curr. Pharm. Des. 2015, 21, 1862-1865. [CrossRef]

Sample Availability: Samples of the compounds are available from the authors and commercially.

(C) 2019 by the authors. Licensee MDPI, Basel, Switzerland. This article is an open access article distributed under the terms and conditions of the Creative Commons Attribution (CC BY) license (http://creativecommons.org/licenses/by/4.0/). 